\title{
Spatiotemporal Dynamics of Nicotinic Acetylcholine Receptors and Lipid Platforms
} AQ1

Francisco J. Barrantes

$1 \square$

Emailrtfjb1@gmail.com

Emailrtfjb1@yahoo.com

1 Faculty of Medical Sciences, Laboratory of Molecular Neurobiology, Institute for Biomedical Research (BIOMED), UCA-CONICET, Av. Alicia Moreau de Justo 1600, C1107AFF Buenos Aires, Argentina

\section{Abstract}

The relationships between neurotransmitter receptors and their membrane environment are complex, mutual (bidirectional) and physiologically important. Some of these relationships are established with subsets of the membrane lipid population, in the form of lipid platforms, lateral heterogeneities of the bilayer lipid having a dynamic chemical composition distinct from that of the bulk membrane. In addition to the equilibrium between the biosynthetic production, exocytic delivery and recycling of receptors on the one hand, and the endocytic internalization on the other, lateral diffusion, clustering and anchorage of receptors at the lipid platforms play key roles in determining the amount of active receptors at the synapse. Mobile receptors traffic between reservoir non-synaptic membranes and the synapse predominantly by thermally driven Brownian motion, and become immobilized at the perisynaptic region or the synapse proper by various mechanisms. These comprise: (a) clustering mediated by homotropic inter-molecular receptor-receptor associations; (b) heterotropic associations with non-receptor scaffolding proteins or the subjacent cytoskeletal meshwork, leading to diffusional "trapping", and (c) protein-lipid interactions, particularly with the neutral lipid cholesterol. Preceded by a brief introduction on the currently used methods to study protein lateral mobility in membranes, this review assesses the contribution of some of these mechanisms to the supramolecular organization and dynamics of the paradigm neurotransmitter receptor of muscle and neuronal cells-the nicotinic acetylcholine receptor (nAChR). The translational mobility of nAChRs at these two cell surfaces differs in terms of diffusion coefficients and residence intervals at the synapse, which cover an ample range of time regimes. Neuronal $\alpha 7 \mathrm{nAChRs}$ exhibit diffusion coefficients similar to those of other neurotransmitter receptors and spend part of their lifetime confined to the perisynaptic region of glutamatergic (excitatory) and GABAergic (inhibitory) synapses; they may also be involved in the regulation of the dynamic equilibrium between excitation and inhibition in brain.

\section{Abbreviations}

$\begin{array}{ll}\alpha \text { BTX } & \alpha \text {-Bungarotoxin } \\ \text { FCS } & \text { Fluorescence correlation spectroscopy } \\ \text { FRAP } & \text { Fluorescence recovery after photobleaching } \\ \text { MSD } & \text { Mean-square displacement } \\ \text { nAChR } & \text { Nicotinic acetylcholine receptor } \\ \text { SPT } & \text { Single particle tracking } \\ \text { TIRF } & \text { Total internal reflection fluorescence }\end{array}$




\subsection{Introduction}

The motion of proteins in cell-surface membranes plays a fundamental role in the communication dynamics of the cell with its external and internal milieux. This is dramatically magnified in the synapse, the subcellular structure specialized in (mostly) chemical and electrical communications between cells. Protein motions depend on a multiplicity of factors: the physicochemical properties of the host lipid bilayer, protein-protein homotropic intermolecular associations, heterotropic association with other proteins (e.g. scaffolding, cell-adhesion, cytoskeletal, or motor proteins) and lipid-protein interactions. Physicochemical properties of the lipid bilayer vary from cell to cell and between different membrane compartments and contribute to the heterogeneity of motional regimes experienced by the same protein in different regions of the cell. By far the most important element that influences diffusional motion in the 2-D plane of the membrane is the degree of association with partner molecules (obviously linked with the dynamic phenomena of crowding and clustering), scaffolding proteins or cytoskeletal barriers (e.g. submembrane actin corrals), or tethering to the cytoskeleton $[1,2,3,4,5]$ or lipid platforms $[6,7,8]$.

In response to acute, mid- (e.g. circadian) and long-term (e.g. denervation supersensitivity) signaling stimuli, and probably in combination with self-regulatory mechanisms, the number and disposition of cell-surface neurotransmitter receptors at the plasma membrane play key roles in determining the functional activity of the synapse, and in particular its strength. This should be envisaged first and foremost in a dynamic perspective: the adaptive changes in the synapse are constantly operative, synaptic receptors being incorporated through active transport, recycling mechanisms, or lateral diffusion, or excluded from the synapse by the latter phenomenon or by various endocytic processes. In the central nervous system (CNS), some of these structural changes may serve for long-term storage of memory. In this review I discuss the idea that the dynamic cross-talk between neurotransmitter receptor molecules and the lipid platforms which serve as their habitats at the cell surface (see recent review in [9]) plays a role in the function of these transient protein-lipid complexes. One can envisage these bilaterat reciprocal interactions as an orchestrated dialogue with mutual modulatory effects: lipids being selected and sorted in from the bulk bilayer by the receptors' structural features and, reciprocally, lipids tuning and optimizing receptor function, in a process which probably evolved over the course of millions of years [10, 11]. The nicotinic acetylcholine receptor ( $\mathrm{AAChR}$ ) protein will be used as the paradigm to analyze these phenomena, and the translational dynamics of this receptor protein compared to those of other neurotransmitter receptor proteins in the CNS.

\subsection{Experimental Approaches to Investigate the Motion of Proteins and Lipid in Membranes}

Various biophysical techniques have been used to address the subject, but three complementary methods have predominated: fluorescence recovery after photobleaching (FRAP) $[12,13]$, fluorescence correlation spectroscopy (FCS) [14, 15, 16, 17, 18, 19, 20], and single-particle (molecule) tracking (SPT) [4, 21, 22, 23, 24, $25,26,27]$. FRAP consists of bleaching an area of the membrane containing the intrinsically (e.g. an incorporated fluorescent protein) or extrinsically labeled proteins or lipids in question with a rapid and relatively intense pulse of light, and then following the time-dependent recovery of the fluorescence signal with a much lower illumination power. The replenishment of the fluorescence signal arises from the diffusion into the photobleached area of fluorescence molecules originally located outside this area. The fluorescence recovery curves are typically characterized by two parameters, a diffusion coefficient (D) and a mobile fraction $\left(\mathrm{M}_{\mathrm{f}}\right)$. FCS is also an ensemble method enabling one to study the dynamics (diffusion coefficient), concentrations and molecular interactions (molecular aggregation, binding-unbinding, co-diffusion of two molecular entities, etc.) with high temporal and spatial resolution by following the passage of fluorescently-labeled molecules through very small volumes of the cell and analyzing the statistics of fluorescence intensity fluctuations as a function of time (see review in [28]). Recently, the combined application of FCS and superresolution optical microscopy (see section below) has enabled the observation of some of the above phenomena down to the nanometer scale (see recent review in [29]). 
SPT can interrogate the motion of membrane proteins in the native membrane milieu of a living cell by following multiple trajectories of a sufficiently large number of single (e.g. fluorescently labeled) molecules and extracting the apparent average diffusion coefficient from the mean-square displacement (MSD) of the molecules. Some shortcomings of these techniques have been pointed out, such as the invasive nature of FRAP, the essentially "local" interrogation of FCS, and the need to observe isolated particles for relatively long periods of time of SPT [30]. The limited spatial and/or temporal resolution of these techniques is still subject to criticism, since they provide a "global" or "macroscopic" diffusion coefficient which reflects the overall mobility over areas of several square microns [31]. In spite of these criticisms, SPT [1, 24, 25, 26, 32] still remains the most common approach for analyzing molecular diffusion in membranes, followed by the FRAP technique (see. e.g. [33, 34, 35, 36]). New analytical tools have appeared in recent years to extend the applicability of SPT analysis to more "real life" (e.g. crowding, anomalous diffusion), complicated membrane environments. One such approach is based on Bayesian and Akaike information criteria in information theory for classifying molecular trajectories $[37,38,39,40]$. The Bayesian method has also been combined with superresolution microscopy techniques such as STED to improve the determination of still positions in subdiffraction images of GPI-anchored membrane proteins [41]. A recent work [42] reviews the "score" resulting from a competition in which 14 available SPT analytical methods were analyzed on the same, complex data set, offering comparisons among SPT methods to address a given biological question.

\subsection{The Nicotinic Acetylcholine Receptor (nAChR) and Its Equilibria at the Synapse}

The nAChR is the prototype of the superfamily of pentameric ligand-gated ion channels, a collection of transmembrane receptor proteins with intrinsic anion-selective channels (the $\gamma$-amino butyric acid type A $\left(\mathrm{GABA}_{\mathrm{A}}\right), \gamma$-amino butyric acid type $\mathrm{C}\left(\mathrm{GABA}_{\mathrm{C}}\right)$ and the glycine receptor) and cation-selective channels as is the case with the 5-HT3 (serotonin) receptor and the nAChR [43, 44]. These transmembrane proteins are composed of five polypeptide subunits organized pseudo-symmetrically around a central pore. Each subunit contains an extracellular domain, four hydrophobic transmembrane segments arranged in the form of three concentric rings around the pore [45] and a short extracellular carboxy-terminal domain [46].

In the peripheral nervous system, at the neuromuscular junction in adult myotubes, the $\mathrm{nAChR}$ macromolecule is highly concentrated in a relatively small area of the cell, packed at the remarkably high density of 10,000-

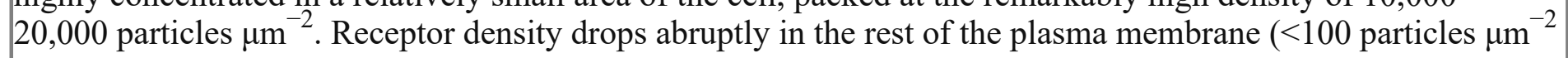
$[47,48])$. Despite this abrupt difference in the density of nAChRs, it has been calculated that the pool of extrasynaptic receptors represents $\sim 99 \%$ of the total amount of receptors present at the cell surface of muscle fibers [49]. As indicated previously, the functional efficacy of the synapse heavily depends on its strength. This in turn is directly related to the number of receptors present at the synapse, which depends on the equilibrium between two sets of factors: (i) lateral diffusion into and out of the synaptic region from non-synaptic ("extrasynaptic") areas, and (ii) the trafficking and turnover of receptors at the cell surface, determined by the rate and extent of biosynthesis and exocytic delivery to the plasmalemma, plus the contribution of receptor recycling back to the surface, on the one hand, and removal of synaptic receptors by internalization (endocytosis) or two-dimensional diffusion driving them away from the synaptic region, on the other. The first of these two phenomena is usually viewed as the equilibrium between a diffuse pool of extrasynaptic receptors and the clustered receptor pool in the synapse. Recent work in C. elegans neuromuscular synapses has shed light on mechanisms modulating this equilibrium: the leucine-rich repeats protein RSU-1 (Ras suppressor-1) is required for the proper distribution of nAChRs on the muscle surface. RSU-1 mutants form ectopic, "illegitimate" extrasynaptic nAChR clusters at the expense of synaptic clusters [50]. The density of nAChRs is also regulated by a complex cascade involving nerve-secreted agrin, activating the muscle-specific kinase MuSK through the protein Lrp4, in association with binding partners dok-7 and Tid1, various kinases and phosphatases and Rho-family small GTPases (reviewed in [51]). Diffusion into the endplate region is also rare except for accidental or man-tailored conditions such as in denervation hypersensitivity, in which migration of extrasynaptic receptors to the motor endplate occurs in a transient fashion. Several pathological conditions of the neuromuscular junction are associated with an insufficient number of receptor molecules, the disease myasthenia gravis probably being the most prominent example. 
In the brain, ACh mediates distant signaling through projection neurons and local signaling via interneurons; the type of message conveyed by ACh depends on a variety of factors, including site of release, the localization of the target neurons, the target receptor subtypes [52] and the status of the target cells at the time of release. Moreover, central cholinergic signaling may be confined to the synapse or involve the de-localized diffusion of the neurotransmitter in the extracellular milieu and binding to non-synaptic sites [53, 54].

In the CNS the dynamics of neurotransmitter receptors at the synapse have been associated with a key physiological phenomenon: synaptic plasticity. Indeed, the rapid lateral exchange of receptors at the synapse with those in non-synaptic areas is thought to underlie the plastic behavior of excitatory glutamatergic synapses (i.e. those operating through AMPA and NMDA receptors, as described below) $[55,56,57,58]$. It has been surmised and supported by a variety of solid experimental approaches that receptors' effective residence time at excitatory synapses directly affects synaptic efficacy and plasticity, that is, long-term potentiation (LTP), longterm depression (LTD) and other biologically important processes which are believed to lie at the root of key cognitive functions such as learning and memory. Furthermore, GABAergic and glycinergic receptors at inhibitory synapses appear to be dynamically regulated through similar processes. Important cognitive functions like learning and memory $[59,60,61]$ may bear relationship with the ability of $\alpha 7 \mathrm{nAChRs}$ to reside intermittently in the neighborhood of glutamatergic and GABAergic synapses, and due to their high $\mathrm{Ca}^{2+}$ permeability, differentially regulate the excitatory/inhibitory balance and LTP in discrete neuronal locations [62, $63,64,65]$.

\subsection{Ontogenetic Changes in nAChR Mobility}

The pioneer study of Axelrod et al. [66] using the fluorescence recovery after photobleaching (FRAP) technique demonstrated that in developing muscle cells the highly clustered nAChRs present in large $(20-60 \mu \mathrm{m})$ patches are practically immobile, with an apparent lateral diffusion coefficient (D) of $<10^{-4} \mu \mathrm{m}^{2} \mathrm{~s}^{-1}\left(<10^{-12} \mathrm{~cm}^{2} \mathrm{~s}^{-1}\right)$. The translational mobility of diffusely distributed nAChRs in other regions of the same plasma membrane is only slightly faster $\left(\mathrm{D} \sim 0.5 \times 10^{-2} \mu \mathrm{m}^{2} \mathrm{~s}^{-1}\right)$. The relative immobility of synaptic nAChRs at the neuromuscular junction is probably due to a multiplicity of factors. The muscle endplate and the electromotor synapse of electric fish are compact "islands" with a huge absolute number of receptor macromolecules densely packed at an extraordinarily high density. It is thus not surprising that receptors hardly diffuse in the plane of the membrane... In order to dissect the contribution of intrinsic (e.g. receptor-receptor interactions, clearly apparent e.g. in early electron micrographs of the Torpedo electroplax postsynaptic membrane [67]) and extrinsic (e.g. corralling by the submembrane cytoskeletal meshwork) protein clustering factors it is useful to resort to simpler model systems. Heterologous constitutive expression of receptors in cells is a compromise system offering the possibility to conduct a variety of studies under physiological conditions. The clonal cell line CHO-K1/A5 [68] robustly expresses adult muscle-type nAChR at densities lower than those of the endplate in an adult muscle cell or the motor plate in the electric fish synapses. Recycling of nAChRs is too slow to contribute to the cell-surface pool within the experimentally observed period [69]. Furthermore, since one has the possibility to increase the complexity of the model system one building block at a time, the lack of non-receptor scaffolding proteins like rapsyn or the clustering factor agrin make the CHO-K1/A5 a useful mammalian expression system to explore "intrinsic" factors involved in clustering and 2-D diffusion of the $\mathrm{nAChR}$ protein and to interrogate in a systematic manner for possible involvement of additional components. AQ2

The 2-D mobility of the adult muscle-type nAChR at the plasma membrane of CHO-K1/A5 cells and its dependence on membrane cholesterol levels were measured using the FRAP technique in the confocal mode (as in $[70,71])$. A defined 2-D region was selected from the confocal section of the cell membrane, thus restricting the analysis to a few thousand fluorescent-tagged nAChRs. The region was photobleached by transiently increasing the laser power of the confocal microscope, and the diffusive exchange of bleached proteins with nearby unbleached molecules was then followed using low-intensity laser excitation. Recovery into the bleached region can be described by two parameters, an apparent lateral diffusion coefficient, D, and a mobile fraction, $\mathrm{Mf}$ $[1,72,73]$. D provides a measure of the kinetics of translational mobility, whereas Mf reports on the proportion 
of fluorescent molecules that are able to diffuse back into the bleached area over the time course of the assay [74]. $\alpha$ BTX-labeled nAChRs exhibited a value of $0.46 \times 10^{-2} \mu \mathrm{m}^{2} \mathrm{~s}^{-1}$ [75], a value similar to that of the mobile $n A C h R$ fraction in developing rat myotubes $\left(0.5 \times 10^{-2} \mu \mathrm{m}^{2} \mathrm{~s}^{-1}\right)$ [66] and that of diffusely distributed nAChR in adult rat muscle fibers in cell culture $\left(0.25 \times 10^{-2} \mu^{2} \mathrm{~s}^{-1}\right)[76,77]$. Methyl- $\beta$-cyclodextrin-mediated depletion of cholesterol produces a reduction in the fraction of mobile nAChRs from 55 to 20\% [75]. Concomitantly, the apparent diffusion coefficient dropped to half the control value. Cholesterol enrichment had the opposite effect.

We subsequently employed the SPT technique in the TIRF model to study nAChR translational diffusion in the same cell model system. Fluorescent-labeled (AlexaFluor ${ }^{488} \alpha$-BTX) nAChR particles imaged with TIRF are diffraction-limited, and puncta of about $0.2 \mu \mathrm{m}$ in diameter could be imaged in wide-field microscopy [78, 79]. The density of these puncta is high, yet there is enough contrast and their separation suffices to track the trajectories with a good signal-to-noise ratio. CHO-K1/A5 cells were labeled with a monovalent ligand (AlexaFluor ${ }^{488} \alpha$-BTX) or a multivalent ligand (anti-nAChR mAb210 monoclonal antibody followed by AlexaFluor ${ }^{488}$-conjugated IgG secondary antibody) at $4{ }^{\circ} \mathrm{C}[80]$. The microscopic apparent diffusion coefficient $\mathrm{D}_{2-4}$ [4] of the receptor labeled with $\alpha$-BTX shifted from a wide distribution spanning from $\sim 6.7 \times 10^{-4}-1 \mu \mathrm{m}^{2}$ $\mathrm{s}^{-4}\left(\sim 6.7 \times 10^{-12}-1 \times 10^{-8} \mathrm{~cm}^{2} \mathrm{~s}^{-1}\right)$ to a much narrower distribution with an upper limit close to $5.0 \times 10^{-4} \mu \mathrm{m}^{2}$ $\mathrm{s}^{-1}$ upon cholesterol depletion [80]. In the case of antibody-labeled samples, the proportion of slow-moving particles was significantly higher, with a net displacement of particle motion towards the immobile confined regime. $\mathrm{D}_{2-4}$ values as low as $\sim 3.3 \times 10^{-5} \mu \mathrm{m}^{2} \mathrm{~s}^{-1}$ (lower limit) to $\sim 6.7 \times 10^{-2} \mu \mathrm{m}^{2} \mathrm{~s}^{-1}$ (upper limit) were observed. Control samples labeled with mAb210 already exhibited a substantial proportion (19.4\%) of immobilized particles. This proportion markedly increased upon cholesterol depletion of the cells, especially during the initial $10 \mathrm{~min}(83.3 \%)$. Simonson and coworkers [81] reported a 2-D diffusion coefficient of 0.1 $\mu \mathrm{m}^{-2} \mathrm{~s}$ for $\alpha 7-5 \mathrm{HT} 3$ chimeric nAChRs heterologously expressed in HEK cells. The quantitative local pointpattern analysis indicated that $\mathrm{nAChR}$ particles were not randomly distributed but organized in clusters, which differed in size, brightness and density between BTX and antibody-treated samples. Interestingly, the density of the $\mathrm{nAChR}$ clusters also varied as a function of time of exposure to methyl- $\beta$-cyclodextrin, reaching a maximum at $\sim 10$ min treatment for BTX-and 20 min for mAb-labeled samples [80].

The scaffolding protein rapsyn affects $\mathrm{nAChR}$ distribution at the cell surface $[82,83,84]$. The myristoylated Nterminus of rapsyn molecules anchors nAChRs to the plasma membrane in a 1:1 stoichiometry, playing a major role during myoblast differentiation and neuromuscular junction development. In myoblasts the majority of the receptors were found to be immobile, with $20 \%$ of the receptors exhibiting restricted diffusion in small domains of about $50 \mathrm{~nm}$ [85]. Before differentiation, only 2\% of the nAChRs showed Brownian diffusion, 24\% diffused in confined regions, and $74 \%$ were immobile. Upon differentiation into multinucleated myoblasts, a strong diminution of the immobile fraction was observed, in conjunction with an increase in the proportion of confined diffusing receptors from 20 to 34\%, and Brownian-diffusing receptors from 2 to $10 \%$. In a myoblast cell line devoid of rapsyn, the fraction of mobile nAChRs was higher, and was accompanied by a 3-fold decrease in the immobile population in comparison to rapsyn-expressing cells. About $50 \%$ of the mobile receptors were confined to domains of about $120 \mathrm{~nm}$. Irrespective of the presence of the nAChR-anchoring protein rapsyn, nAChR was confined to domains: when rapsyn was present, the size of the domains diminished [85]. This study is in agreement with our findings using direct imaging of $\mathrm{nAChR}$ nanoclusters by superresolution microscopy in cells devoid of rapsyn [79].

\subsection{Effect of Cholesterol on nAChR Translational Mobility}

Several FRAP studies have shown that cholesterol depletion affects the mobility of various proteins at the plasma membrane although the nature, extent and sign of the changes remain a contentious subject. In FRAP experiments performed on cells treated with Mevinolin, a statin that inhibits cholesterol biosynthesis, we found that nAChR mobility was affected in a manner similar to that reported here using methyl- $\beta$-cyclodextrin mediated acute cholesterol depletion [75]. FCS in the confocal microscopy modality corroborated the results of FRAP microscopy. Whereas values of D of $5.3 \pm 0.4 \times 10^{-2} \mu \mathrm{m}^{2} \mathrm{~s}^{-1}$ were observed in control cells, D was reduced to $3.7 \pm 0.3 \times 10^{-2} \mu^{2} \mathrm{~s}^{-1}$ upon cholesterol depletion [75]. On the basis of these observations, we can eonelude that plasma membrane fluidity is not the main factor determining $n$ AChR mobility. 
Some authors reported that the mobility of raft- and non-raft resident proteins decreases when cholesterol is removed from the plasma membrane $[74,86]$. Restricted diffusion of membrane proteins upon cholesterol depletion is believed to result from the formation of solid-like clusters in the membrane [87, 88]. Sun et al. (2007) postulate that cholesterol affects the mechanical properties of plasma membrane through the underlying cytoskeleton. Using SPT methods, another group [89] found that cholesterol depletion produces confinement of the epidermal growth factor receptor and human epidermal growth factor receptor 2 mobility, whereas cholesterol enrichment extended the boundaries of the mobility-restricted areas. In contrast, other authors observed an increase in the lateral mobility of the raft-resident proteins CD44 and wild-type GFP-H-Ras after cholesterol depletion $[35,90]$. Removal of cholesterol, particularly with methyl- $\beta$-cyclodextrin, not only alters membrane viscosity but can also hinder membrane protein diffusion [91]. AQ3

\subsection{Cholesterol and Scaffolding Proteins Differentially Affect Neuronal $\alpha_{3}$ and $\alpha_{7}$ nAChR Mobility}

Ciliary ganglion neurons were the first test preparation where $\alpha 7 \mathrm{nAChRs}$ were reported to occur in liquidordered lipid domains ("rafts") in somatic spines [92]. In their quantum dot SPT study of chick ciliary ganglion neurons, Berg and coworkers [93] found that $\alpha 7$ and $\alpha 3 \mathrm{nAChRs}$ had similar mobility, but differed in the nature of their synaptic restraints. Furthermore, cholesterol depletion by treatment with cholesterol oxidase increased the mobility of extrasynaptic $\alpha 3 \mathrm{nAChRs}$ from 0.188 to $0.208 \mu \mathrm{m}^{2} \mathrm{~s}^{-1}$ without affecting the proportion of immobile $\alpha 7$ nAChRs.

In contrast, cholesterol depletion affected both synaptic and extrasynaptic $\alpha 7 \mathrm{nAChRs}$, and the proportion of receptors visiting synaptic territory increased. Cholesterol depletion also raised the proportion of mobile $\alpha 3$ nAChRs from 34 to 54\%, without affecting that of $\alpha 7$ nAChRs. Disruption of PDZ-containing scaffolds or of actin filaments in chick ciliary ganglion neurons increased the mobility of $\alpha 7 \mathrm{nAChRs}$ but not that of $\alpha 3$, as expected from the wealth of evidence on the role of the actin and PDZ-scaffolds in maintaining synapse, and in particular dendritic spine, architecture [94]. It has been previously reported that in one cell, a single species of protein can have one subset undergoing Brownian diffusion and other subsets undergoing confined or anomalous diffusion [95]. Muscle-type nAChR mobility also displays a strong dependence on cytoskeletal integrity [96, 97, $98]$ in developing myotubes and in the adult neuromuscular junction.

\subsection{Diffusional Modulation and Confinement of nAChR Assemblies by Cytoskeletal Components and Scaffolding Proteins}

There is evidence of interactions between lipids, lipid domains and the cytoskeleton (Lenne et al. 2006; Maxfield 2002; Niggli 2001) [99]. According to Kwik et al. (2003) cholesterol depletion produces general effects on the architecture and function of the membrane, making the sub-membrane cytoskeleton and in particular the cortical actin network more stable. Such a reorganization of the actin meshwork would be associated with reduced receptor mobility. Using FCS and STED it was recently shown that membrane-bound actin networks influence lipid phase separation; a model combining the coupling of membrane composition, membrane curvature, and the actin pinning sites was postulated from this study [99]. More recently, confocal FRAP distinguished two protein populations of membrane proteins, including some classical "synaptic" proteins in PC12 cells, having diffusion coefficients D of 0.22 and $0.01 \mu \mathrm{m}^{2} \mathrm{~s}^{-1}$, respectively [100]. When FCS in the superresolution mode (STED-FCS) was applied, the spatio-temporal resolution afforded the determination of D on fast diffusing molecules (slowly diffusing or immobile molecules do not traverse the observation spot and do not cause intensity fluctuations, thus precluding their detection). D was found to be $0.1-0.6 \mu \mathrm{m}^{2} \mathrm{~s}^{-1}$ for the highly mobile protein fractions, which varied inversely proportional to their density. Interestingly, cholesterol level was found to be the most important factor in determining protein mobility and stabilizing protein assemblies (clusters) [100]. 
Cytoskeletal interactions have been shown to modulate the diffusion and confinement of membrane proteins [3, $5,101,102]$. Proteins tethered to highly dynamic actin strands may undergo clustering in response to actin aster formation. Another process involving the actin meshwork and affecting receptor mobility is the formation of fences or pickets, as originally postulated by Kusumi and coworkers [3, 5, 101, 103, 104]. The "picket fence" or "hop diffusion" model postulated that the cortical actin cytoskeletal meshwork underneath the plasma membrane hinders the diffusion of membrane proteins (and lipids) in the plane of the membrane and confines their movement within those boundaries. Occasionally, proteins or lipids confined within these "transient confinement zones" hop these barriers, jumping to a new confined compartment or diffusing more freely in unconfined areas. In the case of the muscle-type nAChR, cholesterol depletion affected the long-range relationship of nAChR nano-clusters of $\sim 55 \mathrm{~nm}$ diameter, changing from a random to a non-random distribution (within a radius of $0.5-$ $1.5 \mu \mathrm{m}$ ) upon depletion [79]. Interactions of these nano-clusters with the cytoskeleton were invoked as a possible explanation for these changes since nAChR mobility at the plasma membrane appears to be sensitive to the integrity of the cytoskeleton $[76,96,97,98]$. Furthermore, interaction between nAChR molecules and the cytoskeleton is of physiological and developmental importance: it is a requisite step in the formation and stability of the neuromuscular junction (Hoch 1999). In subsequent work from our laboratory the effects of cytoskeleton disruption on $\mathrm{nAChR}$ dynamics [75] were experimentally explored. Even though cholesterol depletion-induced loss of nAChR mobility was partially restored in cells incubated with Latrunculin A [75], the percentage of mobile nAChRs in these cells did not reach control levels. From this we concluded that although the cortical actin meshwork is likely involved in receptor mobility at the cell surface in cholesterol-depleted cells, it is not necessarily the only factor influencing nAChR translational diffusion. Other cortical cytoskeletal proteins and/or actin-binding proteins may be involved, and direct interactions of cholesterol with the nAChR may also be implicated. Furthermore, inhibition of actin polymerization by cytochalasin $\mathrm{D}$, which binds to the barbed end of the actin filament and blocks monomer addition, resulted in inhibition of nAChR internalization [69]. However, direct effects of cholesterol on the nAChR cannot be discarded when considering the profound influence of this lipid on the macromolecule's cell surface mobility.

AQ4

Disruption of the cytoskeleton or the microtubule networks with Latrunculin A or nocodazole, respectively, affected the mobility of the neuronal $\alpha 7 \mathrm{nAChR}$ but not its ability to form clusters, as we have observed in muscle-type nAChRs using superresolution microscopy [105]. The exact mechanisms of nAChR immobilization in CNS synapses and in particular the role of the cytoskeleton or other diffusional traps merit further investigation.

Which other factors might contribute to nAChR mobility, trafficking and clustering? Various post-translational modifications are known to occur in nAChRs: the macromolecule is the target of disulphide bond formation, glycosylation, phosphorylation, palmitoylation and other modifications which might affect nAChR dynamics. Palmitoylation of assembling $\alpha 7$ subunits in the endoplasmic reticulum has been shown to play a role in the formation of functional $\alpha$-bungarotoxin sites [106, 107]. A linear relationship has been found between average nAChR half-life and the percentage of nAChRs with phosphorylated $\beta$ subunit in cultured muscle cells. Phosphorylation occurs specifically at tyrosine residue 390 of the $\beta$ subunit, and is induced by agrin. This unexpected role of agrin in downregulating nAChR turnover most likely stabilizes receptors at developing synapses and contributes to their extended half-life at adult NMJs [108]. Phosphorylation-induced global conformational changes have been recently proposed to be a universal phenomenon among ligand-gated ion channels, and also to play a role in pathophysiological phenomena such as nicotine addiction in the specific case of the nAChR [109].

In addition to the above post-translational modifications, antibody crosslinking plays an important role in confining and immobilizing receptors under pathological conditions. Antibody-induced crosslinking results in a strong diminution of receptor mobility in developing rat myotubes in primary culture [110]. Neuromuscular dysfunction in the autoimmune disease myasthenia gravis is caused primarily by the crosslinking of autoantibodies to the muscle endplate nAChR, although other antigens such as muscle-specific tyrosine kinase and low-density lipoprotein receptor-related protein 4 are currently recognized as molecular targets in muscle [111]. Antibody binding results in impaired receptor function, diminished neuromuscular transmission and the 
characteristic weakness and rapid-onset fatigue clinical symptoms. The antibody binding also triggers the endocytic internalization of nAChRs in C2C12 muscle cells and in CHO-K1/A5 cells [69]. This is also observed using the SPT technique in adult-type nAChR expressed in CHO-K1/A5 cells. Instead of the long particle walks observed with the monovalent ligand $\alpha$-BTX, the motion of antibody-crosslinked nAChR particles was restricted to much shorter trajectories confined within relatively small areas [80].

\subsection{Residence Time, Mobility and Function of Neurotransmitter Receptors and Lipid Platforms in the Central Nervous System}

In brain, neuronal excitability depends on the homeostatic equilibrium between inhibitory and excitatory neurotransmission, which is mainly mediated by GABA and glutamic acid, respectively, with additional contributions from other neurotransmitters. The principal excitatory neurotransmitter in brain is glutamic acid. There are various forms of glutamatergic ion channels. They include AMPA ( $\alpha$-amino-3-hydroxy-5-methyl-4isoxazolepropionic acid), kainic acid and N-methyl-D-aspartic acid (NMDA) receptors. These macromolecules having both neurotransmitter receptor and ion channel properties fulfill quite different functions. AMPARs generate fast excitatory postsynaptic potentials by activating non-selective cationic channels permeable to $\mathrm{Na}^{+}$ and $\mathrm{K}^{+}$with an equilibrium potential near $0 \mathrm{mV}$. AMPAR channels are responsible for most of the fast excitatory synaptic transmission in the central nervous system. They are heterotetramers composed of four subunits termed GluR1- GluR4 and contain PDZ-domains: GluR1 binds to SAP1 and GluR2 binds to PICK1 or GRIP/ABP. SAP97 has been postulated to intervene in the trafficking of AMPARs from peri-synaptic to the post-synaptic region and influence glutamatergic transmission. AMPARs do not bind to the ubiquitous PSD-95 scaffolding protein. Clathrin-dependent AMPAR endocytosis in the dendritic spines has been associated with the phenomenon of long-term depression [112].

NMDARs are also heterotetramers formed by two GluN1 and two GluN2 subunits surrounding a cation channel permeable to calcium $[113,114,115]$. NMDARs play a key role in synaptic plasticity and are associated with various forms of learning and memory. NMDARs have been reported to be associated with cholesterol-rich domains in the excitatory synapse [116], which might regulate NMDAR composition, trafficking and ionchannel permeability. Changes in cholesterol content were shown to inhibit NMDA-stimulated $\mathrm{Ca}^{2+}$ influx in hippocampal cells in culture [117]. Cholesterol diminution redistributed the NMDAR GluN2B subunit, from Lo to Ld membrane fractions [117].

The two most abundant forms of $\mathrm{nAChR}$ in brain are the heteropentameric oligomer formed by $\alpha 4$ and $\beta 2$ subunits and the homopentameric receptor formed exclusively by $\alpha 7$ subunits [118]. The $\alpha 7 \mathrm{nAChR}$ is found in the neuronal soma and also in the pre-, post-and peri-synaptic regions. Presynaptic $\alpha 7 \mathrm{nAChRs}$ modulate the release of various neurotransmitters, and postsynaptic $\alpha 7 \mathrm{nAChRs}$ are involved in the generation of postsynaptic currents [119]. Postsynaptic $\alpha 7 \mathrm{nAChRs}$ can be associated with dendritic spines, in a peri-synaptic annulus [120]. Perisynaptic $\alpha 7 \mathrm{nAChRs}$ are found in the vicinity of GABAergic and glutamatergic synapses (see below and e.g. [121]). The $\alpha 7 \mathrm{nAChR}$ exhibits unique functional properties that distinguish it from other nicotinic receptors: (a) fast desensitizing kinetics, (b) unusually high $\mathrm{Ca}^{2+}$ permeability and (c) high affinity for binding $\alpha$ bungarotoxin $[122,123]$. The $\alpha 7 \mathrm{nAChR}$ is highly expressed in the hippocampus and in GABAergic interneurons in particular. The hippocampus is one of the brain regions mostly affected in Alzheimer's disease, where it regulates inhibition of hippocampal networks: activation of $\alpha 7 \mathrm{nAChR}$ blocks the induction of shortterm potentiation as well as LTP. It is involved in cognition and has been associated with pathological states other than Alzheimer's disease, such as some forms of schizophrenia and Parkinson's disease [124].

The residence lifetime of neurotransmitter receptors in the synapse plays an important role in maintaining the inhibitory-excitatory balance. Most neurotransmitter receptors are not permanently anchored to diffusional traps or scaffolding domains at the synapse but appear to freely diffuse in the plane of the membrane at rates between 0.1 and $0.5 \mathrm{~mm}^{2} \mathrm{~s}^{-1}[55,57,102,125,126,127,128]$. Glycine receptors [129] and $\alpha 7 \mathrm{nAChR}$ [121] display similar motional behavior: both exhibit high mobility in extrasynaptic areas and confined, low motion in perisynaptic and synaptic domains. Confinement is inversely correlated to mobility $[121,127,128]$. 
In brain, glycine receptors are stabilized by microtubules in extrasynaptic regions, and by gephyrin and actin filaments in synaptic regions [125]; AMPA receptors become stable upon interaction with the protein GRIP1, which binds in turn to microfilaments [130]. In addition to these anchoring heterotropic interactions with nonreceptor proteins, excitatory GluR1 AMPA receptors are also immobilized transiently at individual synapses by activity, which is input-specific [127]. This relative "trapping" results from the reduction of the diffusional exchange between synaptic and extrasynaptic domains. In other words, AMPA receptors transiently accumulate at distinct sub-regions of the postsynaptic membrane, probably contained within distinct lipid platforms in which receptors experience restricted mobility (median D $0.023 \mu \mathrm{m}^{2} \mathrm{~s}^{-1}$ ). In contrast, AMPA receptors at neighboring inactive synapses are highly mobile (median D $0.138 \mu \mathrm{m}^{2} \mathrm{~s}^{-1}$ ). However, these differences in diffusion coefficients do not account for the net difference in the number of receptors between active and inactive ("silent") synapses: AMPA receptors often escape from silent synapses, whereas they remain trapped in active synapses, which actually capture receptors by diffusional exchange.

In a recent study of inhibitory glycinergic receptors and their scaffolding anchorage protein at the postsynaptic density, gephyrin, PALM time-resolved superresolution microscopy showed that gephyrin clusters are comprised of several sub-clusters, and that these undergo dynamic changes in the time-course of minutes [131]. According to these authors, the morphological changes may correspond to the splitting and merging of gephyrin clusters in the postsynaptic density, whose size determines the number of receptors it can accommodate. Furthermore, the number of the two key inhibitory neurotransmitters - glycine and $\mathrm{GABA}_{\mathrm{A}}$ - increased with the number of gephyrin clusters at spinal cord synapses. This is another reflection of gephyrin's ubiquity in inhibitory synapses: gephyrin is involved in the clustering of both glycine receptors and a major subset of $\mathrm{GABA}_{\mathrm{A}}$ receptors; both compete for the same sites on the gephyrin molecule. Palmitoylation of Cys 212 and Cys 284 in gephyrin has recently been reported to be critical for the association of this protein with the postsynaptic membrane and also essential for its clustering (trimers, hexamers and nonamers) [132]. Lack of palmitoylation leads to mislocalization of gephyrin in non-synaptic regions. Conversely, increased palmitoylation is associated with gain-of-function, i.e. augmented inhibitory GABAergic transmission.

In a study of $\alpha 7 \mathrm{nAChR}$ mobility in cultured hippocampal neurons, SPT was carried out on a small fraction of receptors labeled with quantum dot-coupled $\alpha$-BTX [121]. It should be mentioned that in hippocampal neuronal cultures the GABAergic interneurons are not expected to receive cholinergic innervation, since they are deprived of inputs from distal anatomical brain regions such as the septum. In spite of the absence of synaptic input, $\alpha 7$ nAChRs clusters are present on the neuronal surface. Less than $20 \%$ of the receptors were found in clusters, categorized as "synaptic", as opposed to those labeled with the presynaptic marker synapsin 1, which were assigned to dendritic, postsynaptic, nicotinic sites. The majority $(78 \%)$ of the receptors were found in the form of aggregates in extrasynaptic areas and were either classified as "axonal" $\left(20 \%\right.$, highly mobile, $\mathrm{D}>0.1 \mu \mathrm{m}^{2} \mathrm{~s}^{-1}$, Brownian motion with mostly linear trajectories) or perisynaptic, i.e. in the vicinity of, but not co-localized with, excitatory glutamatergic (identified by mCherry-Homer 1c staining) and inhibitory GABAergic (labeled with EGFP-gephyrin) postsynaptic densities. The $\alpha 7 \mathrm{nAChRs}$ in perisynaptic locations differed in their mobility, too, with lowest receptor mobility ( $>66 \%$ of the "peri-GABAergic" with $\mathrm{D} \sim 0.018 \pm 0.03 \mu \mathrm{m}^{2} \mathrm{~s}^{-1}$ and $>70 \%$ of the "peri-glutamatergic" with $\mathrm{D} \sim 0.028 \pm 0.04 \mu \mathrm{m}^{2} \mathrm{~s}^{-1}$ ), reflecting local confinement domains, these differences suggesting in turn that the tethering mechanisms holding these nicotinic receptors in the vicinity of excitatory and inhibitory synapses differed as well [121]. What are the possible physiological implications of these findings? Stimulation of $\alpha 7 \mathrm{nAChRs}$ in hippocampal interneurons modulates GABAergic inhibitory postsynaptic potentials, depressing them in some cases [133] or exciting them in other instances [134]. In the latter case, the ACh-induced excitation of the bicuculline-sensitive GABAergic interneurons could in turn excite or inhibit pyramidal neurons in the CA1 region. Methyllycaconitine-sensitive $\alpha 7 \mathrm{nAChRs}$ also appear to affect glutamatergic synapses, modulating back-propagating dendritic action potentials and, hence, LTP [135]. Activation of $\alpha 7 \mathrm{nAChRs}$ influences postsynaptic NMDA receptors, relieving the $\mathrm{Mg}^{2+}$ block and thus enhancing the probability of LTP induction [136]. From this type of evidence, the conclusion was reached that their perisynaptic localization and their high $\mathrm{Ca}^{2+}$ permeability endows $\alpha 7 \mathrm{nAChRs}$ with the ability to regulate both excitatory and inhibitory CNS synapses independently of their endogenous transmitter [121]. 
In the synapses between pre- and post-ganglionic neurons in the mouse submandibular ganglion [137], the density of synaptic receptors is normally maintained by the combination of exchange of receptors with nonsynaptic regions, a diffusional phenomenon occurring in the time course of minutes, and the turnover of cell surface receptors, taking place in the course of hours. To measure the kinetics of $\alpha 7 \mathrm{nAChR}, \mathrm{McCann}$ et al. [137] resorted to various techniques. First, using fluorescent $\alpha$-BTX they identified postsynaptic and non-synaptic populations of nAChRs. Postsynaptic nAChRs remained stable for days; non-synaptic nAChRs were more dynamic, being replaced in the course of days. Secondly, using the FRAP technique the authors studied nAChR lateral diffusion in the ganglionic neurons, measuring a $t_{1 / 2}$ of recovery of $47 \pm 7$ min and $11 \pm 4$ min for synaptic and non-synaptic $\alpha 7 \mathrm{nAChR}$ clusters, respectively. Thirdly, to measure the turnover rate of nAChRs in vivo, McCann et al. [137] resorted to a fluorescence and pulse-chase technique [138] which enabled them to follow the fate of the nAChRs in the living animal for several days. The rate of loss of cell-surface neuronal $\alpha 7$ nAChRs ( $350 \pm 47 \mathrm{~min})$ was found to be 60 -fold faster than that of muscle-type nAChRs at the neuromuscular junction [138, 139]. If living ganglion cell axons were severed, synaptic receptors showed enhanced lateral mobility and insertion of new receptors dramatically decreased, leading to near-complete loss of synaptic receptors and to acute synaptic depression. Disappearance of postsynaptic spines and presynaptic terminals ensued [137]. The authors concluded that rapid changes in synaptic efficacy precede long-lasting structural changes in synaptic connectivity. FRAP continues to be applied to the study of neuronal nAChRs. In a recent study, FRAP revealed that the agonist nicotine, acting on $\alpha 7 \mathrm{nAChRs}$ in hippocampal postsynaptic neurons, induces the stabilization and accumulation of GluA1-type AMPA receptors [140].

Chick ciliary ganglion neurons in culture express homomeric $\alpha 7$ and heteromeric $\alpha 3 \mathrm{nAChR}$ at their surface. nAChR lateral mobility was measured using biotinylated $\alpha$-BTX and biotinylated monoclonal antibody against $\alpha 3 \mathrm{nAChRs}$, respectively, followed by streptavidin-coated quantum dots with an emission wavelength of $605 \mathrm{~nm}$ [141]. In the case of $\alpha 3 \mathrm{nAChRs}$, only $34 \%$ were mobile. The resulting diffusion coefficient, D, was reported to be $0.070 \mu^{2} \mathrm{~s}^{-1}$ and $0.188 \mu \mathrm{m}^{2} \mathrm{~s}^{-1}$ in synaptic (roughly $50 \%$ ) and extrasynaptic regions, respectively. In the case of $\alpha 7$ nAChRs the mobile fraction was much higher (61\%) and the measured D was 0.067 and $0.188 \mu \mathrm{m}^{2} \mathrm{~s}^{-1}$ for synaptic and extrasynaptic locations, respectively [141]. The dwell time at the synaptic region was about $0.5 \mathrm{~ms}$ for the two types of neuronal nAChRs. Analysis of the MSD indicated that synaptic receptors exhibited constrained motion, and extrasynaptic receptors displayed Brownian motion. That is, when either type of receptors is able to diffuse freely, they do so at similar rates, but when their motion is restricted, their constraints differ. In adult ciliary ganglia in vivo $\alpha 7 \mathrm{nAChRs}$ are localized in the peri-synaptic region; in cultured neurons, wide-field microscopy immunocytochemistry showed puncta in close proximity to synaptophysin labeling [141].

\subsection{Biomedical Implications}

Keeping synaptic strength at an adequate level is a functional requisite of both peripheral and central nervous system synapses, and it is the combination and homeostasis of the $+/-$ mechanisms outlined above that concertedly operate to maintain the functionally adequate density of neurotransmitter receptors. The mechanisms utilized by cells to achieve this equilibrium are complex, and vary between peripheral and CNS. A common feature is the transient immobilization of receptors in nanoscale compartments of the synapse as opposed to extrasynaptic regions, commonly achieved by clustering or by interaction with scaffolding non-receptor proteins and lipid platforms. Our ability to interrogate the dynamics of receptors is currently limited to brief glimpses of the molecules' entire lifetime, from synthesis to degradation, but nonetheless these snapshots provide useful hints about the organization and the functionally relevant spatiotemporal behavior of these important molecules in the synapse.

Several neurological and neuropsychiatric disorders have been associated with dysfunction of receptors and ion channels at the synapse, whose alterations can be encompassed under the term "synaptopathies". Diseases like depression, anxiety disorders, various forms of dementia, epilepsy, Parkinson's disease, autism spectrum disorder, migraine, fragile X syndrome, and schizophrenia are among these disorders, which cover a wide spectrum of pathological synaptic phenotypes, ranging from alterations in the number, size or morphology of dendritic spines, disposition of spines along the dendritic arborizations, etc. The related alterations in these 
synaptopathies (either hypo- or hyper-function of the synapse) are assumed to depend in turn on the underlying dysfunction of the receptors and channels, the so-called channelopathies [142], which should now be extended to encompass scaffolding and other non-receptor proteins e.g. those misfolded and aggregated at the synapse, like in Alzheimer's, Huntington's or Parkinson's diseases (for recent reviews see e.g. [143, 144]).

\section{Acknowledgements}

Experimental work quoted in this article was supported by grants PICT 2011-0604 from FONCYT, Ministry of Science and Technology and PIP No. $\mathrm{N}^{\circ} 112-201101-01023$ from the National Scientific and Technical Research Council of Argentina (CONICET).

\section{References}

1. Chen Y, Lagerholm BC, Yang B, Jacobson K. Methods to measure the lateral diffusion of membrane lipids and proteins. Methods. 2006;39(2):147-53.

2. Jacobson K, Mouritsen OG, Anderson RG. Lipid rafts: at a crossroad between cell biology and physics. Nat Cell Biol. 2007;9(1):7-14.

3. Kusumi A, Nakada C, Ritchie K, Murase K, Suzuki K, Murakoshi H, Kasai RS, Kondo J, Fujiwara T. Paradigm shift of the plasma membrane concept from the two-dimensional continuum fluid to the partitioned fluid: high-speed single-molecule tracking of membrane molecules. Annu Rev Biophys Biomol Struct. 2005;34:351-78.

4. Kusumi A, Sako Y, Yamamoto M. Confined lateral diffusion of membrane receptors as studied by single particle tracking (nanovid microscopy). Effects of calcium-induced differentiation in cultured epithelial cells. Biophys J. 1993;65(5):2021-40.

5. Suzuki K, Ritchie K, Kajikawa E, Fujiwara T, Kusumi A. Rapid hop diffusion of a G-protein-coupled receptor in the plasma membrane as revealed by single-molecule techniques. Biophys J. 2005;88(5):3659-80.

6. Rao M, Mayor S. Rafts: scale-dependent, active lipid organization at the cell surface. Traffic. 2004;5:231-40.

7. Rao M, Mayor S. Active organization of membrane constituents in living cells. Curr Opin Cell Biol. 2014;29:126-32.

8. Varma R, Mayor S. GPI-anchored proteins are organized in submicron domains at the cell surface. Nature. 1998;394:798-801.

9. Borroni MV, Vallés AS, Barrantes FJ. The lipid habitats of neurotransmitter receptors in brain. Biochim Biophys Acta Biomembr. 2016;1858(11):2662-70.

10. Barrantes FJ. Phylogenetic conservation of protein-lipid motifs in pentameric ligand-gated ion channels. Biochim Biophys Acta Biomembr. 2015;1848(9):1796-805.

11. Barrantes FJ, Fantini J. From hopanoids to cholesterol: molecular clocks of pentameric ligand-gated ion channels. Prog Lipid Res. 2016;63:1-13.

12. Kang M, Day CA, Drake K, Kenworthy AK, DiBenedetto E. A generalization of theory for two-dimensional fluorescence recovery after photobleaching applicable to confocal laser scanning microscopes. Biophys J. 2009;97(5):1501-11. 
13. Petersen NO, Elson EL. Measurements of diffusion and chemical kinetics by fluorescence photobleaching recovery and fluorescence correlation spectroscopy. Methods Enzymol. 1986;130:454-84.

14. Andrade DM, Clausen MP, Keller J, Mueller V, Wu C, Bear JE, Hell SW, Lagerholm BC, Eggeling C. Cortical actin networks induce spatio-temporal confinement of phospholipids in the plasma membrane - a minimally invasive investigation by STED-FCS. Sci Rep. 2015;5. https://doi.org/10.1038/srep11454 .

15. Eggeling C, Ringemann C, Medda R, Schwarzmann G, Sandhoff K, Polyakova S, Belov VN, Hein B, von Middendorff C, Schonle A, Hell SW. Direct observation of the nanoscale dynamics of membrane lipids in a living cell. Nature. 2009;457(7233):1159-62.

16. Elson EL. Quick tour of fluorescence correlation spectroscopy from its inception. J Biomed Opt. 2004;9(5):857-64.

17. Elson EL, Qian H. Interpretation of fluorescence correlation spectroscopy and photobleaching recovery in terms of molecular interactions. Methods Cell Biol. 1989;30:307-32.

18. Schwille P. Fluorescence correlation spectroscopy and its potential for intracellular applications. Cell Biochem Biophys. 2001;34(3):383-408.

19. Schwille P, Haupts U, Maiti S, Webb WW. Molecular dynamics in living cells observed by fluorescence correlation spectroscopy with one- and two-photon excitation. Biophys J. 1999;77(4):2251-65.

20. Sengupta P, Balaji J, Maiti S. Measuring diffusion in cell membranes by fluorescence correlation spectroscopy. Methods. 2002;27(4):374-87.

21. Day CA, Kenworthy AK. Tracking microdomain dynamics in cell membranes. Biochim Biophys Acta. $2009 ; 1788(1): 245-53$.

22. Qian H, Sheetz MP, Elson EL. Single particle tracking. Analysis of diffusion and flow in two-dimensional systems. Biophys J. 1991;60(4):910-21.

23. Saxton MJ. Single-particle tracking: effects of corrals. Biophys J. 1995;69(2):389-98.

24. Saxton MJ, Jacobson KA. Single-particle tracking: applications to membrane dynamics. Annu Rev Biophys Biomol Struct. 1997;26:373-99.

25. Simson R, Sheets ED, Jacobson K. Detection of temporary lateral confinement of membrane proteins using single-particle tracking analysis. Biophys J. 1995;69(3):989-93.

26. Simson R, Yang B, Moore SE, Doherty P, Wash FS, Jacobson KA. Structural mosaicism on the submicron sacale in the plasma membrane. Biophys J. 1998;74(1):297-308.

27. Wu H-M, Lin Y-H, Yen T-C, Hsieh C-L. Nanoscopic substructures of raft-mimetic liquid-ordered membrane domains revealed by high-speed single-particle tracking. Sci Rep. 2016;6:20542.

28. Kim SA, Schwille P. Intracellular applications of fluorescence correlation spectroscopy: prospects for neuroscience. Curr Opin Neurobiol. 2003;13:583-90.

29. Eggeling C, Willig KI, Barrantes FJ. STED microscopy of living cells - new frontiers in membrane and neurobiology. J Neurochem. 2013;126(2):203-12. 
30. Digman M, Gratton E. Imaging barriers to diffusion by pair correlation functions. Biophys J. 2009;97:66573.

31. Sahl S, Leutenegger M, Hell S, Eggeling C. High-resolution tracking of single-molecule diffusion in membranes by confocalized and spatially differentiated fluorescence photon stream recording.

ChemPhysChem. 2014;15(4):771-83.

32. Dietrich C, Yang B, Fujiwara T, Kusumi A, Jacobson K. Relationship of lipid rafts to transient confinement zones detected by single particle tracking. Biophys J. 2002;82(1 Pt 1):274-84.

33. Kapitza HG, McGregor G, Jacobson KA. Direct measurement of lateral transport in membranes by using time-resolved spatial photometry. Proc Natl Acad Sci U S A. 1985;82(12):4122-6.

34. Ladha S, Mackie AR, Clark DC. Cheek cell membrane fluidity measured by fluorescence recovery after photobleaching and steady-state fluorescence anisotropy. J Membr Biol. 1994;142(2):223-8.

35. Niv H, Gutman O, Kloog Y, Henis YI. Activated K-Ras and H-Ras display different interactions with saturable nonraft sites at the surface of live cells. J Cell Biol. 2002;157(5):865-72.

36. Pucadyil TJ, Mukherjee S, Chattopadhyay A. Organization and dynamics of NBD-labeled lipids in membranes analyzed by fluorescence recovery after photobleaching. J Phys Chem B. 2007;111(8):1975-83.

37. Masson JB, Dionne P, Salvatico C, Renner M, Specht CG, Triller A, Dahan M. Mapping the energy and diffusion landscapes of membrane proteins at the cell surface using high-density single-molecule imaging and Bayesian inference: application to the multiscale dynapics of glycine receptors in the neuronal membrane. Biophys J. 2014;106:74-83.

38. Monnier N, Guo S-M, Mori M, He J, Lenart P, Bathe M. Bayesian approach to MSD-based analysis of particle motion in live cells. Biophys J. 2012;103:616-26.

39. Türkcan S, Alexandrou A, Masson JB. A Bayesian inference scheme to extract diffusivity and potential fields from confined single-molecule trajectories. Biophys J. 2012;102:2288-98.

40. Türkcan S, Masson JB. Bayesian decision free for the classification of the model of motion in singlemolecule trajectories. PLoS One. 2013;8:e82799.

41. Manzo C, van Zanten TS, Saha S, Torreno-Pina JA, Mayor S, G.-P. M.F. PSF decomposition of nanoscopy images via Bayesian analysis unravels distinct molecular organization of the cell membrane. Sci Rep. 2014;4:4354.

42. Chenouard N, Smal I, de Chaumont F, Maška M, Sbalzarini IF, Gong Y, Cardinale J, Carthel C, Coraluppi S, Winter M, Cohen AR, Godinez WJ, Rohr K, Kalaidzidis Y, Liang L, Duncan J, Shen H, Xu Y, Magnusson KE, Jaldén J, Blau HM, Paul-Gilloteaux P, Roudot P, Kervrann C, Waharte F, Tinevez JY, Shorte SL, Willemse J, Celler K, van Wezel GP, Dan HW, Tsai YS, Ortiz de Solórzano C, Olivo-Marin JC, Meijering E. Objective comparison of particle tracking methods. Nat Methods. 2014;11:281-9.

43. Cecchini M, Changeux JP. The nicotinic acetylcholine receptor and its prokaryotic homologues: structure, conformational transitions \& allosteric modulation. Neuropharmacology. 2015;96(Pt B):137-49.

44. Nys M, Kesters D, Ulens C. Structural insights into Cys-loop receptor function and ligand recognition. Biochem Pharmacol. 2013;86:1042-53. 
45. Barrantes FJ. Modulation of nicotinic acetylcholine receptor function through the outer and middle rings of transmembrane domains. Curr Opin Drug Discov Devel. 2003;6(5):620-32.

46. Karlin A. Emerging structure of the nicotinic acetylcholine receptors. Nat Rev Neurosci. 2002;3:102-14.

47. Barrantes FJ. Endogenous chemical receptors: some physical aspects. Annu Rev Biophys Bioeng. 1979;8:287-321.

48. Sanes JR, Lichtman JW. Induction, assembly, maturation and maintenance of a postsynaptic apparatus. Nat Rev Neurosci. 2001;2(11):791-805.

49. Salpeter MM, Loring RH. Nicotinic acetylcholine receptors in vertebrate muscle: properties, distribution and neural control. Prog Neurobiol. 1985;25(4):297-325.

50. Pierron M, Pinan-Lucarre B, Bessereau JL. Preventing illegitimate extrasynaptic acetylcholine receptor clustering requires the RSU-1 protein. J Neurosci. 2016;36(24):6525-37.

51. Burden SJ, Yumoto N, Zhang W. The role of MuSK in synapse formation and neuromuscular disease. Cold Spring Harb Perspect Biol. 2013;5(5):a009167.

52. Picciotto MR, Higley MJ, Mineur YS. Acetylcholine as a neuromodulator: cholinergic signaling shapes nervous system function and behavior. Neuron. 2012;76(1):116-29.

53. Descarries L, Gisiger V, Steriade M. Diffuse transmission by acetylcholine in the CNS. Prog Neurobiol. 1997;53(5):603-25.

54. Descarries L, Parent M. Chapter 14 - Asynaptic and synaptic innervation by acetylcholine neurons of the central nervous system. In: Pickel V, Segal M, editors. The synapse. Boston: Academic Press; 2014. p. 44766 .

55. Choquet $\mathrm{D}$, Triller A. The role of receptor diffusion in the organization of the postsynaptic membrane. Nat Rev Neurosci. 2003;4(4):251-65.

56. Choquet D, Triller A. The dynamic synapse. Neuron. 2013;80:691-703.

57. Holcman D, Triller A. Modeling synaptic dynamics driven by receptor lateral diffusion. Biophys J. 2006;91(7):2405-15.

58. Triller A, Choquet D. New concepts in synaptic biology derived from single-molecule imaging. Neuron. 2008;59(3):359-74.

59. Bear MF, Malenka RC. Synaptic plasticity: LTP and LTD. Curr Opin Neurobiol. 1994;4(3):389-99.

60. Kroker KS, Rast G, Rosenbrock H. Differential effects of subtype-specific nicotinic acetylcholine receptor agonists on early and late hippocampal LTP. Eur J Pharmacol. 2011;671(1-3):26-32.

61. Stevens C. A millon dollar question: does LTP = memory? Neuron. 1998;20:1-2.

62. Chen L, Yamada K, Nabeshima T, Sokabe M. $\alpha 7$ nicotinic acetylcholine receptor as a target to rescue deficit in hippocampal LTP induction in $\beta$-amyloid infused rats. Neuropharmacology. 2006;50(2):254-68. 
63. Ma L, Turner D, Zhang J, Wang Q, Wang M, Shen J, Zhang S, Wu J. Deficits of synaptic functions in hippocampal slices prepared from aged mice null $\alpha 7$ nicotinic acetylcholine receptors. Neurosci Lett. 2014;570:97-101.

64. Ondrejcak T, Wang Q, Kew JNC, Virley DJ, Upton N, Anwyl R, Rowan MJ. Activation of $\alpha 7$ nicotinic acetylcholine receptors persistently enhances hippocampal synaptic transmission and prevents $\mathrm{A} \beta$-mediated inhibition of LTP in the rat hippocampus. Eur J Pharmacol. 2012;677(1-3):63-70.

65. Broide RS, Leslie FM. The alpha7 nicotinic acetylcholine receptor in neuronal plasticity. Mol Neurobiol. 1999;20(1):1-16.

66. Axelrod D, Koppel DE, Schlessinger J, Elson E, Webb WW. Mobility measurement by analysis of fluorescence photobleaching recovery kinetics. Biophys J. 1976;16(9):1055-69.

67. Heuser JE, Salpeter SR. Organization of acetylcholine receptors in quick-frozen, deep-etched, and rotaryreplicated Torpedo postsynaptic membrane. J Cell Biol. 1979;82:150-73.

68. Roccamo AM, Pediconi MF, Aztiria E, Zanello L, Wolstenholme A, Barrantes FJ. Cells defective in sphingolipids biosynthesis express low amounts of muscle nicotinic acetylcholine receptor. Eur J Neurosci. 1999;11(5):1615-23.

69. Kumari S, Borroni V, Chaudhry A, Chanda B, Massol R, Mayor S, Barrantes FJ. Nicotinic acetylcholine receptor is internalized via a Rac-dependent, dynamin-independent endocytic pathway. J Cell Biol. 2008;181(7):1179-93.

70. Nehls S, Snapp EL, Cole NB, Zaal KJ, Kenworthy AK, Roberts TH, Ellenberg J, Presley JF, Siggia E, Lippincott-Schwartz J. Dynamics and retention of misfolded proteins in native ER membranes. Nat Cell Biol. 2000;2(5):288-95.

71. Zaal KJ, Smith CL, Polishchuk RS, Altan N, Cole NB, Ellenberg J, Hirschberg K, Presley JF, Roberts TH, Siggia E, Phair RD, Lippincott-Schwartz J. Golgi membranes are absorbed into and reemerge from the ER during mitosis. Cell. 1999;99(6):589-601.

72. Edidin M. Fluorescence photobleaching and recovery, FPR, in the analysis of membrane structure and dynamics. In: Damjanocich S, Edidin M, Szollosi J, editors. Mobility and proximity in biological membranes. Boca Raton, FL: CRC Press; 1994. p. 109-35.

73. Guo L, Har JY, Sankaran J, Hong Y, Kannan B, Wohland T. Molecular diffusion measurement in lipid bilayers over wide concentration ranges: a comparative study. ChemPhysChem. 2008;9(5):721-8.

74. Kenworthy AK, Nichols BJ, Remmert CL, Hendrix GM, Kumar M, Zimmerberg J, Lippincott-Schwartz J. Dynamics of putative raft-associated proteins at the cell surface. J Cell Biol. 2004;165(5):735-46.

75. Baier CJ, Gallegos CE, Levi V, Barrantes FJ. Cholesterol modulation of nicotinic acetylcholine receptor surface mobility. Eur Biophys J. 2010;39(2):213-27.

76. Stya M, Axelrod D. Mobility and detergent extractability of acetylcholine receptors on cultured rat myotubes: a correlation. J Cell Biol. 1983;97:48-51.

77. Stya M, Axelrod D. Mobility of extrajunctional acetylcholine receptors on denervated adult muscle fibers. J Neurosci. 1984;4:70-4. 
78. Borroni V, Baier CJ, Lang T, Bonini I, White MM, Garbus I, Barrantes FJ. Cholesterol depletion activates rapid internalization of submicron-sized acetylcholine receptor domains at the cell membrane. Mol Membr Biol. 2007;24(1):1-15.

79. Kellner RR, Baier CJ, Willig KI, Hell SW, Barrantes FJ. Nanoscale organization of nicotinic acetylcholine receptors revealed by stimulated emission depletion microscopy. Neuroscience. 2007;144(1):135-43.

80. Almarza G, Sanchez F, Barrantes FJ. Transient cholesterol effects on nicotinic acetylcholine receptor cellsurface mobility. PLoS One. 2014;9(6):e100346.

81. Simonson PD, DeBerg HA, Ge P, Alexander JK, Jeyifous O, Green WN, Selvin PR. Counting bungarotoxin binding sites of nicotinic acetylcholine receptors in mammalian cells with high signal/noise ratios. Biophys J. 2010;99(10):L81-3.

82. Barrantes FJ, Neugebauer DC, Zingsheim HP. Peptide extraction by alkaline treatment is accompanied by rearrangement of the membrane-bound acetylcholine receptor from Torpedo marmorata. FEBS Lett. 1980;112(1):73-8.

83. Burden SJ, Depalma RL, Gottesman GS. Crosslinking of proteins in acetylcholine receptor-rich membranes: association between the $\beta$-subunit and the $43 \mathrm{kd}$ subsynaptic protein. Cell. 1983;35:687-92.

84. Ramarao MK, Cohen JB. Mechanism of nicotinic acetylcholine receptor cluster formation by rapsyn. Proc Natl Acad Sci U S A. 1998;95:4007-12.

85. Piguet J, Schreiter C, Segura J, Voguel H, Hovius R. Acetylcholine receptor organization in membrane domains in muscle cells: evidence for rapsyn-independent and rapsyn-dependent mechanisms. Int J Biol Chem. 2011:363-9.

86. O'Connell KM, Tamkun MM. Targeting of voltage-gated potassium channel isoforms to distinct cell surface microdomains. J Cell Sci. 2005;118(Pt 10):2155-66.

87. Nishimura SY, Vrljic M, Klein LO, McConnell HM, Moerner WE. Cholesterol depletion induces solid-like regions in the plasma membrane. Biophys J. 2006;90(3):927-38.

88. Vrljic M, Nishimura SY, Moerner WE, McConnell HM. Cholesterol depletion suppresses the translational diffusion of class II major histocompatibility complex proteins in the plasma membrane. Biophys J. 2005;88(1):334-47.

89. Orr G, Hu D, Ozcelik S, Opresko LK, Wiley HS, Colson SD. Cholesterol dictates the freedom of EGF receptors and HER2 in the plane of the membrane. Biophys J. 2005;89(2):1362-73.

90. Oliferenko S, Paiha K, Harder T, Gerke V, Schwarzler C, Schwarz H, Beug H, Gunthert U, Huber LA. Analysis of CD44-containing lipid rafts: recruitment of annexin II and stabilization by the actin cytoskeleton. J Cell Biol. 1999;146(4):843-54.

91. Shvartsman DE, Gutman O, Tietz A, Henis YI. Cyclodextrins but not compactin inhibit the lateral diffusion of membrane proteins independent of cholesterol. Traffic. 2006;7(7):917-26.

92. Bruses J, Chauvet N, Rutishauser U. Membrane lipid rafts are necessary for the maintenance of the (alpha)7 nicotinic acetylcholine receptor in somatic spines of ciliary neurons. J Neurosci. 2001;21(2):504-12. 
LA. Characterization of Eag1 channel lateral mobility in rat hippocampal cultures by single-particle-tracking with quantum dots. PLoS One. 2010;5(1):e8858.

94. Hotulainen P, Hoogenraad CC. Actin in dendritic spines: connecting dynamics to function. J Cell Biol. 2010;189(4):619-29.

95. Feder TJ, Brust-Mascher I, Slattery JP, Baird B, Webb WW. Constrained diffusion or immobile fraction on cell surfaces: a new interpretation. Biophys J. 1996;70(6):2767-73.

96. Bloch RJ, Velez M, Krikorian JG, Axelrod D. Microfilaments and actin-associated proteins at sites of membrane-substrate attachment within acetylcholine receptor clusters. Exp Cell Res. 1989;182:583-96.

97. Dai Z, Luo X, Xie H, Peng HB. The actin-driven movement and formation of acetylcholine receptor clusters. J Cell Biol. 2000;150(6):1321-34.

98. Pumplin DW, Strong JC. Acetylcholine receptor clusters of rat myotubes have at least three domains with distinctive cytoskeletal and membranous components. J Cell Biol. 1989;109:739-53.

99. Honigmann A, Sadeghi S, Keller J, Hell SW, Eggeling C, Vink R. A lipid bound actin meshwork organizes liquid phase separation in model membranes. Elife. 2014;3:e01671.

100. Saka SK, Honigmann A, Eggeling C, Hell SW, Lang T, Rizzoli SO. Multi-protein assemblies underlie the mesoscale organization of the plasma membrane. Nat Commun. 2014;5:1-14.

101. Kusumi A, Ike H, Nakada C, Murase K, Fujiwara T. Single-molecule tracking of membrane molecules: plasma membrane compartmentalization and dynamic assembly of raft-philic signaling molecules. Semin Immunol. 2005;17(1):3-21.

102. Triller A, Choquet D. Synaptic structure and diffusion dynamics of synaptic receptors. Biol Cell. 2003;95(7):465-76.

103. Kusumi A, Suzuki K. Toward understanding the dynamics of membrane-raft-based molecular interactions. Biochim Biophys Acta. 2005;1746(3):234-51.

104. Ritchie K, Shan XY, Kondo J, Iwasawa K, Fujiwara T, Kusumi A. Detection of non-Brownian diffusion in the cell membrane in single molecule tracking. Biophys J. 2005;88(3):2266-77.

105. Wenz JJ, Borroni V, Barrantes FJ. Statistical analysis of high-resolution light microscope images reveals effects of cytoskeleton-disrupting drugs on the membrane organization of the nicotinic acetylcholine receptor. J Membr Biol. 2010;235(3):163-75.

106. Alexander JK, Govind AP, Drisdel RC, Blanton MP, Vallejo Y, Lam TT, Green WN. Palmitoylation of nicotinic acetylcholine receptors. J Mol Neurosci. 2010;40:12-20.

107. Drisdel RC, Manzana E, Green WN. The role of palmitoylation in functional expression of nicotinic alpha7 receptors. J Neurosci. 2004;24:10502-10.

108. Rudell JB, Ferns MJ. Regulation of muscle acetylcholine receptor turnover by $\beta$ subunit tyrosine phosphorylation. Dev Neurobiol. 2013;73:399-410.

109. Talwar S, Lynch JW. Phosphorylation mediated structural and functional changes in pentameric ligand- 
gated ion channels: implications for drug discovery. Int J Biochem Cell Biol. 2014;53:218-23.

110. Axelrod D. Crosslinkage and visualization of acetylcholine receptors on myotubes with biotinylated alphabungarotoxin and fluorescent avidin. Proc Natl Acad Sci U S A. 1980;77(8):4823-7.

111. Sieb JP. Myasthenia gravis: an update for the clinician. Clin Exp Immunol. 2014;175(3):408-18.

112. Huganir RL, Nicoll RA. AMPARs and synaptic plasticity: the last 25 years. Neuron. 2013;80(3):704-17.

113. Bashir ZI, Alford S, Davies SN, Randall AD, Collingridge GL. Long-term potentiation of NMDA receptormediated synaptic transmission in the hippocampus. Nature. 1991;349(6305):156-8.

114. Cui Z, Wang H, Tan Y, Zaia KA, Zhang S, Tsien JZ. Inducible and reversible NR1 knockout reveals crucial role of the NMDA receptor in preserving remote memories in the brain. Neuron. 2004;41(5):781-93.

115. Li F, Tsien JZ. Memory and the NMDA receptors. N Engl J Med. 2009;361(3):302-3.

116. Besshoh S, Bawa D, Teves L, Wallace MC, Gurd JW. Increased phosphorylation and redistribution of NMDA receptors between synaptic lipid rafts and post-synaptic densities following transient global ischemia in the rat brain. J Neurochem. 2005;93(1):186-94.

117. Frank C, Giammarioli AM, Pepponi R, Fiorentini C, Rufini S. Cholesterol perturbing agents inhibit NMDA-dependent calcium influx in rat hippocampal primary culture. FEBS Lett. 2004;566(1-3):25-9.

118. Gotti C, Clementi F, Fornari A, Gaimarri A, Guiducci S, Manfredi I, Moretti M, Pedrazzi P, Pucci L, Zoli M. Structural and functional diversity of native brain neuronal nicotinic receptors. Biochem Pharmacol. 2009;78:703-11.

119. Cuevas J, Berg DK. Mammalian nicotinic receptors with alpha7 subunits that slowly desensitize and rapidly recover from alpha-bungarotoxin blockade. J Neurosci. 1998;18:10335-44.

120. Fabian-Fine R, Skehel P, Errington ML, Davies HA, Sher E, Stewart MG, Fine A. Ultrastructural distribution of the 7 nicotinic acetylcholine receptor subunit in rat hippocampus. J Neurosci. 2001;21:7993 8003.

121. Buerli T, Baer K, Ewers H, Sidler C, Fuhrer C, Fritschy JM. Single particle tracking of alpha7 nicotinic AChR in hippocampal neurons reveals regulated confinement at glutamatergic and GABAergic perisynaptic sites. PLoS One. 2010;5(7):e11507.

122. Alkondon M, Pereira EF, Barbosa CT, Albuquerque EX. Neuronal nicotinic acetylcholine receptor activation modulates gamma-aminobutyric acid release from CA1 neurons of rat hippocampal slices. Pharmacol Exp Ther. 1997;283:1396-411.

123. Alkondon MA, E.X. The nicotinic acetylcholine receptor subtypes and their function in the hippocampus and cerebral cortex. Prog Brain Res. 2004;145:109-20.

124. Banerjee C, Nyengaard JR, Wevers A, de Vos RA, Jansen Steur EN, Lindstrom J, Pilz K, Nowacki S, Bloch W, Schroder H. Cellular expression of alpha7 nicotinic acetylcholine receptor protein in the temporal cortex in Alzheimer's and Parkinson's disease-a stereological approach. Neurobiol Dis. 2000;7:666-72.

125. Charrier C, Ehrensperger MV, Dahan M, Levy S, Triller A. Cytoskeleton regulation of glycine receptor 
number at synapses and diffusion in the plasma membrane. J Neurosci. 2006;26:8502-11.

126. Dahan M, Levi S, Luccardini C, Rostaing P, Riveau B, Triller A. Diffusion dynamics of glycine receptors revealed by single-quantum dot tracking. Science. 2003;302(5644):442-5.

127. Ehlers MD, Heine M, Groc L, Lee MC, Choquet D. Diffusional trapping of GluR1 AMPA receptors by input-specific synaptic activity. Neuron. 2007;54(3):447-60.

128. Meier J, Vannier C, Serge A, Triller A, Choquet D. Fast and reversible trapping of surface glycine receptors by gephyrin. Nat Neurosci. 2001;4(3):253-60.

129. Ehrensperger MV, Hanus C, Vannier C, Triller A, Dahan M. Multiple associations states between glycine receptors and gephyrin identified by SPT analysis. Biophys J. 2007;92:442-5.

130. Allison DW, Gelfand VI, Spector I, Craig AM. Role of actin in anchoring postsynaptic receptors in cultured hippocampal neurons: differential attachment of NMDA versus AMPA receptors. J Neurosci.

1998;18:2423-36.

131. Specht C, Izeddin I, Rodriguez PC, El Beheiry M, Rostaing P, Darzacq X, Dahan M, Triller A. Quantitative nanoscopy of inhibitory synapses: counting gephyrin molecules and receptor binding sites. Neuron. 2013;79:308-21.

132. Dejanovic B, Semtner M, Ebert S, Lamkemeyer T, Neuser F, Lüscher B, Meier JC, Schwarz G. Palmitoylation of gephyrin controls receptor clustering and plasticity of GABAergic synapses. PLoS Biol. 2014;12:e1001908.

133. Wanaverbecq N, Semyanov A, Pavlov I, Walker MC, Kullmann DM. Cholinergic axons modulate GABAergic signaling among hippocampal interneurons via postsynaptic alpha 7 nicotinic receptors. J Neurosci. 2007;27:5683-93.

134. Ji D, Dani JA. Inhibition and disinhibition of pyramidal neurons by activation of nicotinic receptors on hippocampal interneurons. J Neurophysiol. 2000;83:2682-90.

135. Rosza B, Katona G, Kaszas A, Szipocs R, Vizi ES. Dendritic nicotinic receptors modulated backpropagating action potentials and long-term plasticity of interneurons. Eur J Neurosci. 2008;27:36477.

136. Dani JA, Bertrand D. Nicotinic acetylcholine receptors and nicotinic choliergic mechanisms of the central nervous system. Annu Rev Pharmacol Toxicol. 2007;47:699-729.

137. McCann CM, Tapia JC, Kim H, Coggan JS, Lichtman JW. Rapid and modifiable neurotransmitter receptor dynamics at a neuronal synapse in vivo. Nat Neurosci. 2008;11(7):807-15.

138. Akaaboune M, Cullican SM, Turney SG, Lichtman JW. Rapid and reversible effect of activity on acetylcholine receptor density at the neuromuscular junction in vivo. Science. 1999;286:503-7.

139. Bruneau EG, Akaaboune M. The dynamics of recycled acetylcholine receptors at the neuromuscular junction in vivo. Development. 2006;133(22):4485-93.

140. Halff AW, Gómez-Varela D, John D, Berg DK. A novel mechanism for nicotinic potentiation of glutamatergic synapses. J Neurosci. 2014;34(6):2051-64. 
141. Fernandes CC, Berg DK, Gomez-Varela D. Lateral mobility of nicotinic acetylcholine receptors on neurons is determined by receptor composition, local domain, and cell type. J Neurosci. 2010;30(26):8841-51.

142. Kass RS. The channelopathies: novel insights into molecular and genetic mechanisms of human disease. J Clin Invest. 2005;115:1986-9.

143. Perez-Lloret S, Barrantes FJ. Deficits in cholinergic neurotransmission and their clinical correlates in Parkinson's disease. NPJ Parkinsons Dis. 2016;2:16001.

144. Remmers C, Sweet RA, Penzes P. Abnormal kalirin signaling in neuropsychiatric disorders. Brain Res Bull. 2014;103:29-38. 